\title{
IMPLEMENTASI NILAI-NILAI PENDIDIKAN ISLAM TERHADAP ADAT MOGAMA' PADA MASYARAKAT NUANGAN 1 KABUPATEN BOLAANG MONGONDOW.
}

\author{
Hamlan Andi Baso Malla \\ Dosen Fakultas Tarbiyah dan Ilmu Keguruan Institut Agama Islam Negeri (IAIN) Palu \\ hamlan@iainpalu.ac.id \\ Sjakir Lobud \\ Dosen Fakultas Tarbiyah Ilmu dan Keguruan Institut Agama Islam Negeri (IAIN) Palu \\ sjakirlobud@iainpalu.ac.id \\ Muhammad Agung Kadengkang \\ Mahasiswa Fakultas Tarbiyah dan Ilmu Keguruan Institut Agama Islam Negeri (IAIN) Palu \\ agung.kadengkang97@gmail.com
}

\section{Abstract}

This study deals with "Implementation of Islamic education values to the MoGama tradition 'in the community of Nuangan 1 Village, Bolaang Mongondow Regency". The main discussion in this study is the view of Islam in the 13 implementation of the Gama 'tradition in the village of Nuangan 1 Bolaang Mongondow Regency, and the educational values contained in the stages/implementation of the Gama' custom in the village of Nuangan 1. The purpose of this study is to find out the Islamic view in the 13 stages of the implementation of Gama' and the values of education in the implementation of Gama' in the village of Nuangan 1. This research is qualitative descriptive and viewed with a qualitative approach. Data collection methods include: observation, interviews, documentation, while the data collection is obtained from village heads, traditional leaders, religious leaders and community leaders by presenting data, reducing data, and verifying data. The results of this study are (1) the Islamic view of adat gama' containing the values of Islamic teachings, namely (a) glorifying women. (b) Gathering (c) please help. (d) courtesy of guest. (e) wish for blessing with prayer together. (2) Values of Education in 13 stages Indigenous gamma' (a) treat women well. (b) respect women. (c) treat women well. (d) strengthen family relationships. (e) love women with love. ( $f$ ) thanks to the female companion who carries an umbrella, $(g)$ being gentle to women. (h) be nice to guests. (i) introduce the bride to the groom's family. (j) thanks to pandamping for accompanying the bride. (k) treat guests well. (l) light hands always give. $(m)$ pray for a newlywed.

Key words: islamic education values, MoGama' customs, 


\begin{abstract}
Abstrak
Penelitian ini berkenaan dengas 15 rentasi nilai-nilai perdidikan Islam terhadap adat MoGama r...........syarakat Desa Nuangan 1 Kabupaten Bolaang Mongondow". Pokok pembahasan dalam penelitian ini ialah pandangan Islam dalam 13 pelaksanaan adat Gama' di desa Nuangan 1 Kabupaten Bolaang Mongondow, dan nilai-nilai pendidikan yang terkandung di dalam tahapan/pelaksanaan adat Gama' di desa Nuangan 1. tujuan penelitian ini adalah untuk mengetahui pandangan Islam dalam 13 tahap pelaksanaan adat Gama' dan nilai-nilai pendidikan dalam pelaksanaan adat gama' di desa Nuangan 1. Penelitian ini bersifat deskritif kualitatif dan dilihat dengan pendekatan kualitatif. metode pengumpulan datanya meliputi: obsevasi, wawancara, dokumentasi, sedangkan sember data peroleh dari kepala desa, tokoh adat, tokoh agama dan tokoh masyarakat dengan penyajian data, reduksi data, dan verifikasi data. Hasil penelitian ini ialah (1) pandangan Islam terhadap adat gama' mengandung nilai-nilai ajaran Islam yaitu (a) memuliakan wanita. (b) Silaturahmi (c) tolong menolong. (d) adab memuliakan tamu. (e) mengharapkan keberkahan dengan doa bersama. (2) nilai_nilai Pendidikan Dalam 13 tahap Adat gama': (a) memperlakukan wanita dengan baik. (b) mengahargai wanita. (c) mempelakukan wanita dengan baik. (d) memperkuat hubungan keluarga. (e) menyayangi wanita dengan kasi sayang. (f) ucapan terimakasih kepada pendamping wanita yang membawa payung.(g) bersikap halus kepada wanita. (h) bersikap baik kepada tamu. (i) memperkenalkan pengantin wanita kepada keluarga pengantin pria. (j) ucapan terimakasih kepada pandamping karena sudah menemani pengantin wanita. (k) menjamu tamu dengan baik. (l) ringan tangan selalu memberi. (m) mendoakan pengantin baru.
\end{abstract}

Kata kunci: nilai-nilai pendidikan islam, adat MoGama’.

\title{
Pendahuluan
}

Islam adalah nama dari agama yang telah dianugerahkan oleh Allah Swt kepada manusia sebagai falsafah dan sandaran hidup. Di dalamnya mengandung ajaran yang "membimbing dan menggiring akal pikiran, jiwa, qalbu, inderawi dan jasmani kepada kefitrahan yang selalu cenderung untuk berbuat ketaatan dan ketauhidan kepada yang maha pencipta". Dengan demikian Islam mengandung pengertian serangkaian peraturan yang didasarkan pada wahyu yang diturunkan oleh

${ }^{1}$ Abuddin Nata, Metodologi Studi Islam, (Jakarta: PT, Raja Grafindo Persada,2010), h. 13. 
Allah Swt. kepada para nabi/rasul untuk ditaati dalam rangka memelihara keselamatan, kesejahteraan, dan konsep agama Islam 39 perdamaian bagi umat manusia yang termaktub dalam kitab suci. Islam merupakan satu-satunya agama yang diturunkan oleh Allah Swt. kepada manusia melalui para nabi/rasul-Nya mulai dari nabi Adam a.s. hingga nabi Muhammad Saw. Inti ajaran Islam yang dibawa oleh para nabi ini adalah satu, yaitu tauhid, yakni mengesakan Allah atau menuhankan Allah yang Esa. Tidak ada satu pun di antara para nabi Allah yang mengajarkan prinsip ketuhanan yang bertentangan dengan tauhid.

Pendidikan adalah segala daya upaya dan semua usaha untuk membuat masyarakat dapat mengembangkan potensi manusia agar memiliki kekuatan spiritual keagamaan, pengendalian diri, berkepribadian, memiliki kecerdasan, berakhlak mulia, serta memiliki keterampilan yang diperlukan sebagai anggota masyarakat dan warga negara. Di samping itu pendidikan merupakan usaha untuk membentuk manusia yang utuh lahir dan batin cerdas, sehat, dan berbudi pekerti luhur. Pendidikan merupakan proses belajar yang tak akan ada berhentinya. Berbagai macam cara dapat dilakukan untuk memperoleh pendidikan yang mana kita biasanya mengetahui bahwa pendidikan identik dengan dunia sekolah. Namun perlu diketahui bahwa segala sesuatu yang adadi dunia ini dapat kita peroleh nilai-nilai pendidikanya. Seperti nasihat-nasihat dari keluarga terutama adalah orang tua, kondisi lingkungan sekitar, respon alam, membaca berbagai literatur, dan lain sebagainya. Menurut Mortiner J. Adler, dalam Khoiron Rosyadi, yang mendefinisikan bahwa yang dimaksud pendidikan adalah:

Proses di mana semua kemampuan manusia (bakat dan kemampuan yang diperoleh) yang dapat dipengaruhi oleh pembiasaan, disempurnakan dengan kebiasaan yang baik melalui sarana yang dibuat dan dipakai oleh siapa pun untuk membantu orang lain atau dirinya sendiri mencapai tujuan yang ditetapkan. Sehingga dengan demikian dapat di ketahui bahwa pendidikan merupakan usaha pembinaan dan pengembangan potensi manusia secara optimal sesuai dengan statusnya, dengan berpedoman kepada syariat Islam yang disampaikan oleh Rasul Allah yang setia dengan segala aktivitasnya guna tercipta suatu kondisi kehidupan Islam yang ideal, selamat, aman, sejahtera dan berkualitas serta memperoleh jaminan (kesejahteraan) hidup di dunia dan jaminan bagi kehidupan yang baik di akhirat. $^{2}$ 
Sedangkan menurut Acmadi Pendidikan Islam dapat diartikan sebagai segala usaha untuk memelihara dan mengembangkan fitrah manusia serta sumber daya manusia yang ada padanya menuju terbentuknya manusia seutuhnya (insan kamil) sesuai dengan moral Islam, yakni untuk membentuk manusia yang beriman dan bertakwa serta memiliki berbagai kemampuan yang teraktualisasi dalam hubungannya dengan Allah SWT, dengan sesama manusia dan alam sekitarnya. ${ }^{3}$

Menurut Kamus Besar Bahasa Indonesia adat adalah “yang lazim diturut atau dilakukan sejak dahulu kala." ${ }^{4}$ Adat adalah ketentuan leluhur dan ditaati secara turun temurun. Ia merupakan tradisi yang mengatur masyarakat penduduk asli Indonesia yang dirasakan olehanggota-anggotanya sangat mengikat sebagai kaidah-kaidah sosial yang dianggap sakral, maka pelaksanaan adat ini hendaknya di laksanakan berdasarkan norma-norma adat yang berlaku disetiap daerah. Adat menjadi salah satu peraturan yang menata kehidupan manusia. Adat pertama kali dikenal oleh seseorang dari lingkungan keluarga, kemudian meluas menjadi bagian dalam masyarakat. Dari kedua lingkungan inilah adat turut membentuk kepribadian manusia, yaitu sebagai pembimbing dan pengarah dalam kehidupannya. Jadi adat dapat diartikan sebagai aturan yang lazim dituruti atau dilakukan sejak dahulu kala, baik dilingkungan keluarga maupun ditengah masyarakat.

Budaya terbentuk dari banyak unsur yang rumit, termasuk sistem agama dan politik, adat istiadat, bahasa, perkakas, pakaian, bangunan, dan karya seni. Bahasa, sebagaimana juga budaya, merupakan bagian tak terpisahkan dari diri manusia sehingga banyak orang cenderung menganggapnya diwariskan secara genetis. Ketika seseorang berusaha berkomunikasi dengan orang-orang yang berbada budaya dan menyesuaikan perbedaan-perbedaannya, membuktikan bahwa budaya itu dipelajari.

Indonesia adalah negara yang banyak memiliki kebudayaan dan tradisi yang sangat unik disetiap daerahnya. Banyak kebudayaan dan tradisi itulah yang masih dipertahankan hingga saat ini. Kebudayaan di Indonesia khususnya di Bolaang Mongondow, ada adat pernkawinan yang cukup menarik. Adat tersebut terkenal dengan nama "Gama". Kata "Gama" berasal dari bahasa mongondow yang artinya “Ambil". Berbicara tentang adat tidak lepas dari peran Guhanga, karena peran

${ }^{3}$ Achmadi, Idiologi Pendidikan Islam; Paradigma Humanisme Teosentris, (Yogyakarta: Pustaka Belajar, 2005), h. 28-29.

${ }^{4}$ Departemen Pendidikan dan Kebudayaan, Kamus Besar Bahasa Indonesia Edisi kedua, (Jakarta; Balai Pustaka, 2009). h. 6. 
Guhanga erat kaitannya dengan adat istiadat. Keberadaannya tidak hanya menjadi pelaksana adat yang kental dengan pencitraan atau ketentuan adat yang simbolik dan mengembangkan budaya dengan corak kesukuan. Tetapi dalam banyak hal, tidak terkecuali terkait dinamisnya sebuah pemerintahan, relasi sosial antar masyarakat bahkan pembebasan tanah dan batas wilayah menjadi persoalan keseharian yang tidak pernah luput dari keterlibatan Guhanga "kepala adat" Sampai sekarang ini beberapa bagian Adat Bolaang Mongondow masih dipatuhi dan dihormati masyarakat. Antara lain ketika mengadakan pesta pernikahan, upacara kematian "Tonggoluan" dan tata cara berpakaian, upacara menjemput pengantin wanita oleh keluarga pengantin pria, penjemputan tamu kehormatan dan pemberian gelar kehormatan.

Upacara adat pernikahan yang dilakukan masyarakat Bolaang Mongondow pada intinya tetap sama meskipun terdapat perbedaan-perbedaan dalam pelaksanaannya, dimana banyak bagian-bagian yang tidak berlaku lagi. Fokus penelitian ini terdapat pada salahsatu Adat daerah Bolaang Mongondow Timur (Suku Mongondow). Adat Gama’ dilaksanakan untuk menjemput pengantin wanita sebagai bentuk penghargaan. Gama' jika diartikan dalam Bahasa Indonesia yaitu 'ambil', adat gama'dapat diartikan mengambil atau penerimaan secara hormat oleh keluarga mempelai pria terhadap pengantin wanita dengan menjemput wanita dirumahnya dan dibawa kerumah penganti pria untuk di perkenalkan dengan semua keluarga pengantin pria.

Mengacu pada persoalan di atas maka penulis dapat merumuskan permasalahan sebagai berikut:

a. Bagaimana pandangan Islam terhadap 13 tahapan adat MoGama' di desa Nuangan 1 Kabupaten Bolaang Mongondow?

b. Bagaimana Nilai-Nilai Pendidikan Islam di dalam 13 tahapan adat MoGama' di desa Nuangan 1 Kabupaten Bolaang Mongondow?

\section{Metode Penelitian}

Jenis penelitian adalah "penelitian lapangan (field research)", ${ }^{5}$ dimana peneliti mencari rumusan terhadap permasalahan yang diteliti dengan menyesuaikan pada kondisi lingkungan penelitian yang natural, dan keterlibatan peneliti yang minimal.

${ }^{5}$ Nur Indriantoro dan Bambang Supomo, Metodologi Penelitian Bisnis Untuk Akutansi dan Menejemen, (Ed I; Yogyakarta, BPFE UGM, 2009), h. 92. 
"Peneliti akan mendiskripsikan data-data yang terkait dengan permasalahan dalam penelitian, kemudian peneliti sebagai instrumen kunci melakukan penekanan makna terhadap kondisi obyek alamiah yang diteliti secara kualitatif'. ${ }^{6}$

Sebagaimana yang diterangkan oleh Matthew B. Miles dan A. Michel Humberman yaitu:

Singkatnya, hal-hal apa yang terdapat dalam analisis kualitatif? Pertama, data yang muncul berwujud kata-kata dan bukan rangkaian angka. Data itu mungkin telah dikumpul dalam aneka macam cara (observasi, wawancara, intisari, dokumen, pita rekaman), dan yang biasa "diproses" kira-kira sebelum siap digunakan (melalui pencatatan, pengetikan, penyuntingan, atau ahli tulis). Tetapi analisis kualitatif ini tetap mengunakan kata-kata yang bisa disusun dalam teks yang luas. ${ }^{7}$

Penelitian ini diwujudkan dengan menafsirkan satu variabel data kemudian menghubungkan dengan variabel data yang lain dan disajikan dalam bentuk kata-kata atau kalimat naratif. Digunakannya pendekatan kulitatif dalam skripsi ini bersifat mendiskripsikan tentang Pandangan Islam terhadap adat Gama' dan Nilai-Nilai Pendidikan (Studi pada Masyarakat Desa Nuangan 1 Kabupaten Bolaang Mongondow Timur).

Untuk memperoleh data yang obyektif dan valid, data yang dikumpulkan adalah berupa data yang kualitatif yang terdiri dari sejumlah data primer dan sekunder. Data primer adalah data yang diperoleh lannsung dari sumbernya dan dicatat untuk pertama kalinya. Sumber data primer yang diambil di desa Nuangan peneliti mendapatkan data yang meliputi adat Gama', dari kepala desa Nuangan 1, tokoh adat, tokoh agama dan tokoh masyarakat. Data sekunder adalah data yang bukan diusahakan sendiri pengumpulannya oleh peneliti, berupa asrip, jurnal, artikel, paper dan makalah-makalah yang berhubungan dengan obyek penelitian. ${ }^{8}$

\section{Pembahasan}

\section{Pandangan Islam Terhadap adat MoGama'.}

Islam adalah agama yang diajarkan oleh Nabi Muhammad SAW berpedoman pada kitab suci Al-Qur'an, yang diturunkan ke dunia melalui wahyu Allah SWT.

${ }^{6}$ Sugiyono, Metode Penelitian Bisnis, (Bandung, Alfabeta, 2008), h. 8.

${ }^{7}$ Matthew B Milles, Et.Al, Qualitative Data Analisys, diterjamahkan oleh Tetjep Rohendi Rohidi Dengan Judul Analisis Data Kualitatif, Buku Tentang Metode-Metode Baru (Cet.I; Jakarta: UI - Press, 2007), h. 15-16.

IIbid., h. 8. 
Agama Islam merupakan sistem tata kehidupan yang pasti bisa menjadikan manusia damai, bahagia, dan sejahtera. Islam adalah Agama yang Paling sempurna, karena semuanya ada dalam Islam, Islam yang dibawa Nabi Muhammad Saw yang hingga sekarang masih tetap mempertahankan ajaran tauhid dan semua ajaran lain yang secara rinci telah termaktub dalam kitab suci al-Quran. Kitab al-Quran yang masih tetap autentik memberi jaminan akan orisinalitas ajaran Islam yang dibawa oleh Nabi Muhammad Saw. hingga sekarang. Islam inilah yang merupakan agama terakhir yang berlaku untuk semua umat manusia hingga akhir zaman. Rasulullah Saw selalu mengajak umatnya untuk selalu menjalankan apa yang di perintahkan Allah Swt dan menjauhi laranganya.

Perkawinan merupakan ikatan lahir dan batin yang memiliki tujuan dalam hidup agar terjalin rumah tangga yang sakinah mawaddah warrahmah, disisi lain juga rumah tangga dalam perkawinan akan menjadi harmonis dengan nilai-nilai yang terjalin dalam keluarga, begitu juga di desa nuangan 1 Kabupaten Bolaang Mongondow Timur adat Gama mengandung nilai-nilai Islam terhadap 13 tahapan pelaksanaan adat gama' di desa Nuangan 1 Kabupaten Bolaang Mongondow Timur. Sebagai mana hasil wawancara dengan Tokoh Agama Bapak Masuri Dakotalot S.Pd.i berkaitan dengan pandangan Islam terhadap adat Gama' sebagai berikut:

"Pandangan Islam tentang adat Gama di desa Nuangan 1 Kabupaten Bolaang Mongondow Timur yang berkaitan dengan 13 tahap pelaksanaan di dalam adat Gama, di mana dalam pelaksanaan adat Gama ini banyak nilai-nilai kebaikan (positif) sesuai dengan ajaran Islam dalam pelaksanaan adat Gama secara keseluruhan dan tidak bertantangan dengan Islam. Diantaranya tenatang memuliakan seorang wanita, silaturahmi, tolong menolong dalam kebaikan, adab memuliakan tamu yang datang brkunjung kerumah dan mengharapkan keberkahan dari Allah Swt dengan doa bersama".

Berdasarkan hasil wawancara di atas dengan Tokoh Agama Bapak Masuri Dakotalot S.Pd.i maka penulis bisa menyimpulakan Pandangan Islam terhadap adat Gama’ dengan melihat nilai-nilai Islam yang ada di dalam 13 tahap adat gama' di Desa Nuangan 1 Kabupaten Bolaang Mongondow Timur, tidak bertentangan dengan ajaran Islam.

${ }^{9}$ Masuri Dakotalot S.Pd.i, Tokoh Agama Desa Nuangan 1. "Wawancara”, 7 juni 2019. 
1. Tahap-tahap pelaksanaan Adat MoGama'

Upacara adat mogama' ini menurut adat Bolaang Mongondow Timur merupakan keharusan yang harus dilakukan sebab sanksinya pengantin wanita tidak diperkenankan untuk berkunjung kerumah pengantin pria seumur hidupnya karena orang Mongondow sangant menjunjung tinggi kehormatan "Harkat Wanita". Apabila tidak dilaksanakan maka ada sanksi adat yang disebut "Butungon" artinya tabu atau kualat karena rangkaian adat diperkawinan daerah Bolaang Mongondow baru lengkap apabila upacara adat Gama' di desa Nuangan 1 Kabupaten Bolaang Mongondow Timur ini dilaksanakan. Adapun tahapan nya sebagai berikut:

a. Pangkoy gama': "Pohon Ambil"

Pengantin wanita dihiasi lengkap dengan pakaian pengantin, duduk ditengahtengah ruangan dalam rumah, berkrudung menutup mata dan dinaungi paying. Anak laki-laki memohon restu kepada orang tua mantu perempuan (Ibu) sambil memberikan seserahan dan menyampaikan bahasa adat : Mama naadon akuoy ki mamangoy don moguat takin adat bo bahasa koyi anu' monimu yo aka motaaw mama popo halalpa ondadon in lopi bo ulatmu selama pinomantalan,pinolahiran , pinomiagan sampe siya tana'a pinobuloy kudon simba rumah tangga naminda umur padoman mononoy bain sidutu matoy yo aka poduduy in ibogku ba bulud in ambang bo in popountuku kui anu' monimu yo mama tonga'pa naa in popo abatk sin akuoy diya' kounu bounu. Dijawab oleh Ibu mertua : O'o uyo niondon iko bonopik takin adat bobahasa yo popohalal kubi' ondadon in lopi bo ulatku bo umpaka bulud in ambang popountunmu koyi anu'ku yo mo ondok akuoy sindika ka asi kianu'ku tonga' sempe-sempetenmu. Jika pengantin laki-laki dan Ibu mertua tidak bisa membahasakan bahasa adat maka akan dibahasakan oleh penegak adat. Sejalan dengan pelakasanaan adat gama pada tahapan pertama, sebagaimana hasil wawancara dengan tokoh adat desa Nuangan 1 Bapak Asirin Paputungan, bahwa:

“Pangkoi Gama' artinya (pohon ambil) pertama proses adat, dalam tahapan ini pengantin wanita dihiasi lengkap dengan gaun pengantin serta berkrudung menutupi muka, dan ditahap ini pengantin pria meminta restu kepada orang tua pengantin wanita sambil memberikan seserahan dan menyampaikan bahasa adat dengan maksud meminta izin kepada orang tua pengantin wanita agar meberikan tanggung jawab anaknya diberikan sepenuhnya kepada mempelai pria dan kemudian dijawab oleh menantu dengan bahasa adat yang artinya sudah 
mengikhlaskan anaknya untukberpindah tanggung jabaw kepada pengantin pria $" 10$

Senada dengan pernyataan diatas kepala desa Nuangan 1 Bapak Fuad Bazmul sebagai kepala Desa Nuangan 1 mengatakan sebagai berikut: "dalam tahap pertama adat gama dimna seorang pengantin pria bertamu keruma mempelai wamita dengan maksud menjuemput pengantin wanita utuk diperkenalkan dengan keluarga pengantin pria" $^{\text {"11 }}$

b. Polampangon Kontutugan Lanag: "meninggalkan rumah pengantin wanita"

Pengantin wamita belum mau berjalan sehingga seseorang Ibu harus membujuk dengan halus sambil menyerahkan seserahan. Anak Perempuan dijemput oleh salah seorang ibu dari kel. Laki-laki sambil memberikan seserehan dan berucap : Anu' lampangdon mangoi kontutugan lanag ta'poigumon konbarakat i togi kahendak ondadon in tabeat tadiya' mopiya yo ta'padoman modudu na'doman tubig in uyan tu monop na'doman lanag. Dibawah sampai ke pinggiran sungai/ got/ draenase. Hasil Wawancara dengan tokoh adat desa Nuangan 1 bapak Asirin Paputungan sebagai guhanga mengenai tahap kedua dalam adat gama sebagai berikut:

"Polampang kontutugan lanag (meninggalkan rumah pengantin wanita) disini pengantin wanita mongula atau malu-malu sehingga salah satu keluarga dari pengantin pria menagajak dan memberikan seserahan dan membahasakan dengan halus agar pengantin wanita mau pergi bersama rombongan mempelai pria". ${ }^{12}$

Mengenai tahap kedua ini penulis juga mewawancarai kepala Desa Nuangan 1 Bapak Fuad Bazmul sebagai berikut: "Disini pengantin wanita dijemput keluarga mempelai pria dan meberikan seserahan dan mebujuk pengantin wanita untuk ikut pergi bersama dengan pengantin pria unruk bertemu dengan keluarga dari mempelai pria" ${ }^{\prime 13}$

c. Polampangon Kontubig : melewati sungai, selokan

Disini pengantin wanita dengan sikap mongula, artinya bertahan karena harga diri sehingga merasa enggan untuk melangkah lebih lanjut. Anak perempuan dijemput oleh salah seorang ibu dari kel. Laki-laki sambil memberikan seserehan dan berucap:

${ }^{10}$ Asirin Paputungan, Ketua Adat Desa Nuangan 1 Kabupaten Bolaang Mongondow Timur. "Wawancara", 3 Juni 2019.

${ }^{11}$ Fuad Bazmul, Kepala Desa Nuangan 1. "Wawancara”, 4 Juni 2019.

${ }^{12}$ Asirin Paputungan, Ketua Adat Desa Nuangan 1 Kabupaten Bolaang Mongondow Timur. "Wawancara", 3 Juni 2019.

${ }^{13}$ Fuad Bazmul, Kepala Desa Nuangan 1. "Wawancara”, 4 Juni 2019. 
Yo anu' lolan don iko kontubig ta' poiguman koitogi kawasa ondadon inta diya' mopiya nion kon badanmu, kon ginamu,bo kompikiranmu yo ta'padoman moilig kon tubig bodiyaannya modapot kon balangon ta diya' ko ontongan diya' kolongowan Bodiya'koyimpoyan. Ketiga proses ini dilakasanakan dirumah keluarga perempuan kemudian dibawa kerumah anak laki-laki. Anak perempuan dijemput oleh salah seorang ibu dari kel. Laki-laki sambil memberikan seserehan dan berucap : Anu' poponik don mangoy iko kon tukad sin iko deeman bidon tonga' mokokiangoy sin nobali bidon in intau bonu baloy. Hasil wawancara dengan ketua adat desa Nuangan 1 gama’ bapak Asirin Paputungan sebagai berikut:"Polampangon Kontubig (melewati sungai, selokan) pengantin wanita meninggalkan rumuah bersama rombongan menuju rumah pengantin pria sambil memberikan seserahan kepada pengantin wanita". ${ }^{14}$

Hasil Wanwancara dengan sekdes desa Nuangan 1 bapak Abubakar Alhabsyi sebagai sekertaris Desa Nuangan 1 sebagai berikut: "Ditahap ini keluarga pengantin pria meberikan seserahan kepada penagantin wanita mengajak untuk pergi kerumah pengantin pria dan diperkenalkan kepada keluarga pengantin Pria". ${ }^{15}$

d. Poponikan Kon Tukad : " menaiki bambambu"

Pengantin wanita berjalan menuju tolatak dan didepan tolatak pengantin wanita berhenti sejenak sambil mongula sebelum melangkah naik ke tolatak. Meberikan seserahan sebagai tanda ikatan kekeluargaan yang akrab, selanjutnya Mokapit (menggandeng) tangan pengantin wanita dan dituuntun melewati tolatak menuju rumah pengantin pria. Hasil wawancara dengan tokoh adat desa Nuangan 1 Bapak Asirin Paputungan sebagai berikut :"poponikan kon tukad (menaiki bambambu) ditahap ini pengantin wanita mulai memasuki halaman rumah pengantin pria dan masi mongula sehingga keluarga menjumput dan memberikan seserahan kepada penagantin wanita". ${ }^{16}$

\footnotetext{
${ }^{14}$ Asirin Paputungan, Ketua Adat Desa Nuangan 1 Kabupaten Bolaang Mongondow Timur. "Wawancara", 3 Juni 2019.

${ }^{15}$ Abubakar Alhabsyi, Sekertaris Desa Nuangan 1. "Wawancara", 4 Juni 2019.

${ }^{16}$ Asirin Paputungan, Ketua Adat Desa Nuangan 1 Kabupaten Bolaang Mongondow Timur. "Wawancara", 3 Juni 2019.
} 
Hasil wawancara dengan Sekertaris Desa Nuangan 1 Bapak Abubakar Alhabsyi sebagai berikut: "penagntin wanita sudah sampai di halam rumah pengantin pria sambil mongula dan di berikan sesajian dari keluarga pengantin pria". ${ }^{17}$

e. Lampang Kon Tanom : "pengantin wanita sampai diteras rumah pengantin pria”.

Pengantin wanita berhenti diambang pintu rumah, disambut oleh ibu kandung dan saudara kandung pengantin pria. Dengan penuh gembira dan kasih sayang menyambut kedatangan pengantin wanita seraya menjabat tangan sambil memberikan seserahan. Hasil wawancara dengan tokoh adat nuangan 1 Bapak Asirin Paputungan sebagai berikut:

"Lampang Kon Tanom (pengantin wanita sampai diteras rumah pengantin pria) pengantin wanita sudah sampai di depan pintu rumah penagantin pria langsung di jemput oleh orang tua dan keluarga penagntin pria dengan gembira dan diberikan seserahan". ${ }^{18}$

Hasil wawancara dengan kepala desa Nuangan 1 Bapak Fuad Bazmul sebagai berikut: "pengantin wanita disambut oleh orang tua pengantin pria denagan meriah dan diberikan seserahan dan mempersilahkan pengantin wanita masuk ke dalam rumah " ${ }^{19}$

f. Pilat in payung: "payung ditutup"

Payung di kerungkum oleh seseorang pembawa payung setelah memberikan seserahan kepada pengantin wanita, dan pembawa payung diberikan penghargaan. Hasil wawancar dengan tokoh adat Bapak Asirin Paputungan sebagai berikut: "pilat in payung (payung ditutup) pembawa payung yang menemani pengantin wanita sepanjang perjalanan menutup payung setelah diberikan seserahan". ${ }^{20}$

Hasil wawancara kepalah desa Nuangan 1 dengan Bapak Fauad Bazmul sebagai berikut: "pembawa payung mendampingi pengantin wanita menutup payung setelah meberikan seserahan dan pihak keluarga pengantin pria juga memberikan seserahan kepada pembawa payung". ${ }^{21}$

\footnotetext{
17 Abubakar Alhabsyi, Sekertaris Desa Nuangan 1. "Wawancara", 4 Juni 2019.

18 Asirin Paputungan, Ketua Adat Desa Nuangan 1 Kabupaten Bolaang Mongondow Timur. "Wawancara", 3 Juni 2019.

${ }^{19}$ Fuad Bazmul, Kepala Desa Nuangan 1. “Wawancara”, 4 Juni 2019.

${ }^{20}$ Asirin Paputungan, Ketua Adat Desa Nuangan 1 Kecamatan Nuangan Kabupaten Bolaang Mongondow Timur. “Wawancara”, 3 Juni 2019.

${ }^{21}$ Fuad Bazmul, Kepala Desa Nuangan 1. "Wawancara", 4 Juni 2019.
} 


\section{g. Pilat In Siripu : "Melepas Sendal"}

Keluarga mempelai Laki-laki memberikan seserahan namun pengantin wanita masi mongula. Pengantin wanita masi bersikap malu, rendah hati dan manja. Anak perempuan dijemput oleh salah seorang ibu dari kel. Laki-laki sambil memberikan seserehan dan berucap : Yo anu pilat pa in siripumu ba oyuonka in nokoritakanmu andeka noki tondoday kon ilampanganmu barang mosindip yomobayag padoman Barang molanit yomongangoy padoman barang moruit mopupud padoman. Hasil wawancara dengan tokoh adat bapak Asirin Paputungan sebagai berikut: "Pilat In Siripu (Melepas Sendal) pengantin wanita melapas sandal dan dijemput orang tua dan memberikan seserahan dan mempersilahkan penagantin wanita dan pendamping masuk didalam rumah" ${ }^{\prime 22}$

Hasil wawancara dengan kepala desa Nuangan 1 Bapak Fuad Bazmul sebagai berikut: "penagantin wantita melepas sandal dan di persilahkan masuk kedalam rumah oleh leluarga mempelai pria dan sambil memberikan seserahan". ${ }^{23}$

h. Ilitu'an/ Bahasa'an Mopolitu' : "Pengantin Wanita di persilahkan Duduk"

Pengantin diperintahkan duduk dan diajak bicara oleh keluarga mempelai pria sambil diberikan seserahan dan berucap: Anu yo litu'don sin iko no dapot bidon. Hasil wawancara dengan Bapak Asirin Paputungan sebagai berikut: "penagantin disuru duduk dan diajak berbicara oleh keluarga penagantin pria dan keluarga mempelai pria memberikan seserahan kepada penagantin wanita". ${ }^{24}$

Hasil wawancara dengan Bapak Abubakar Alhabsyi sebagai Berikut: "pengantin wanita dipersilahkan duduk oleh orang tua pengantin pria dan diajak berbicara dibarengi dengan memberikan sesajian kepada pengantin wanita". ${ }^{25}$

i. Pilat In Kokudu : "Melepas Kerudung"

Anak perempuan di suruh buka penutup wajah oleh salah seorang ibu dari kel. Laki-laki sambil memberikan seserehan dan berucap : Yo anu aka motaaw pilatanpa kokuduk sin ba ontongon pa nami in pogotmu. Hasil wawancar denagn tokoh adat Bapak Asirin Paputungan sebagai berikut:

\footnotetext{
${ }^{22}$ Asirin Paputungan, Ketua Adat Desa Nuangan 1 Kabupaten Bolaang Mongondow Timur. "Wawancara", 3 Juni 2019.

${ }^{23}$ Fuad Bazmul, Kepala Desa Nuangan 1. "Wawancara”, 4 Juni 2019.

${ }^{24}$ Asirin Paputungan, Ketua Adat Desa Nuangan 1 Kabupaten Bolaang Mongondow Timur. "Wawancara”, 3 Juni 2019.

${ }^{25}$ Abubakar Alhabsyi, Sekertaris Desa Nuangan 1. "Wawancara”, 4 Juni 2019.
} 
"pilat in kokudung (melepas penutup wajah) pengantin wanita diberikan seserahan oleh orang tua penagntin pria dan memohon agar penagntin wanita membuka penutup muka yang menutupi muka penagantin wanita agar disaksikan oleh keluarga penagntin pria". ${ }^{26}$

Hasil wawancara dengan kepalah desa Nuangan 1 Bapak Fuad Bazmul sebagai Berikut: "pengantin wanita diperintahkan oleh orang tua penagntin pria untuk membuka pentup wajah sambil memberikan seserahan supaya keluarga dari penagntin pria bisa melihat wajah penagantin wanita". ${ }^{27}$

j. Pinogapangan : "memberikan pengahrgaan kepada pendamping wanita"

Seorang ibu memberikan seserahan kepada pendamping wanita, sebagai ucapan terimakasi sudah mendampingi mempelai wanita sampai kerumah mempelai pria. Hasil wawancar denagn tokoh adat Bapak Asirin Paputungan sebagai berikut: "pinogapangan (ucapan terimakasi kepada pendamping pengantin wanita) orang tua mempelai pria memberikan seserahan uang kepada pendamping wanita karena sdah menemani mempelai wanita datang kerumah" ${ }^{\text {28 }}$

Hasil wawancara dengan sekdes desa Nuangan 1 Bapak Abubakar Alhabsyi sebagai Berikut: "keluarga pengantin pria memberikan uang kepada pendamping wanita sebagai tanda ucapan terimakasi karena sudah mau menemani penagantin wanita". 29

\section{k. Pinomama'an : "Makan Bersama"}

pengantin lelaki disuruh duduk dan makan bersama oleh salah seorang ibu dari kel. Laki-laki sambil memberikan seserehan dan berucap :Anu aka motaaw ki buloymu lipitupa mogapang bo mongaan takinmu, disediakan sirih pinang dan alat makan. Hasil wawancar dengan tokoh adat Bapak Asirin Paputungan sebagai berikut: "pinomama'an (makan bersama) makan bersama keluarga pengantin wanita dan pria habis makan keluarga pengantin pria memberikan lagi seserahan kepada pengantin wanita",30

${ }^{26}$ Asirin Paputungan, Ketua Adat Desa Nuangan 1 Kecamatan Nuangan Kabupaten Bolaang Mongondow Timur. "Wawancara”, 3 Juni 2019.

${ }^{27}$ Fuad Bazmul, Kepala Desa Nuangan 1. "Wawancara”, 4 Juni 2019.

28 Asirin Paputungan, Ketua Adat Desa Nuangan 1 Kabupaten Bolaang Mongondow Timur. "Wawancara", 3 Juni 2019.

${ }^{29}$ Abubakar Alhabsyi, Sekertaris Desa Nuangan 1. "Wawancara", 4 Juni 2019.

30 Asirin Paputungan, Ketua Adat (Guhanga) Desa Nuangan 1 Kabupaten Bolaang Mongondow Timur. “Wawancara”, 3 Juni 2019. 
Hasil wawancara dengan sekdes desa Nuangan 1 Bapak Abubakar Alhabsyi sebagai Berikut: "pengantin pria dan wanita makan bersama denagn keluarga dan diberikan seserahan setelah pengantin wanita selesai makan". ${ }^{31}$

1. Pokilimumugan : "Disuruh Berkumur"

Anak Perempuan disuruh berkumur oleh salah seorang ibu dari kel. Laki-laki sambil memberikan seserehan dan berucap : Anu polimumugdon iko. Pada tahapan selanjut nya: Ponentengan penegak adat mengetuk piring kosong sambil mengucap: Yo aka uyonpa in keluarga utat andeka guyanga tadiya'pa namangoy nolongow yo inggaidon, anggota keluarga dari pihak lelaki yang belum memberikan seserehan disilahkan untuk memberikan secara ihklas..dan uang/atau barang diberikan kepada Pengantin perempuan. Hasil wawancar dengan tokoh adat Bapak Asirin Paputungan sebagai berikut: "pokilimumugan (disuruhub berkumur) pengantin wanita disuru berkumur dan diberikan seserahan oleh semua keluarga mempelai pria",32

Hasil wawancara dengan kepalah desa Nuangan 1 Bapak Fuad Bazmul sebagai Berikut: "pengantin perintakan berkumur lalu ditumpahkan diwadah yang sudah disediakan dan diberikan seserahan yang berharga dari semua keluarga pengantin pria yang hadir",33

m. Pobuian : "Pulang"

Penegak adat dari pihak Wanita memohon pamit untuk pulang dari rumah acara ditutup dengan doa bersama. Hasil wawancar dengan tokoh adat Bapak Asirin Paputungan sebagai berikut: "Tahap teakhir ditutup dengan doa bermasa keluarga penagntin wanita dengan keluarga pengantin pria yang di pimpin ustad yang hadir" ${ }^{34}$

Hasil wawancara dengan kepalah desa Nuangan 1 Bapak Fuad Bazmul sebagai Berikut: "Ucapan terimakasi dari pihak penagantin pria kepada pendamping wanita karena sdah menemani pengantin di Gama' dan doa bersama yang dipimpin ustad yang hadir". 35

\footnotetext{
31 Abubakar Alhabsyi, Sekertaris Desa Nuangan 1. "Wawancara", 4 Juni 2019.

32 Asirin Paputungan, Ketua Adat (Guhanga) Desa Nuangan 1 Kabupaten Bolaang Mongondow Timur. "Wawancara”, 3 Juni 2019.

${ }^{33}$ Fuad T Bazmul, Kepala Desa (Sangadi) Nuangan 1. "Wawancara”, 4 Juni 2019.

34 Asirin Paputungan, Ketua Adat (Guhanga) Desa Nuangan 1 Kabupaten Bolaang Mongondow Timur. "Wanancara”, 3 Juni 2019.

${ }^{35}$ Fuad T Bazmul, Kepala Desa (Sangadi) Nuangan 1. "Wawancara”, 4 Juni 2019.
} 


\section{Nilai-Nilai Pendidikan Islam di Dalam 13 Tahap Adat MoGama' di Desa Nuangan 1 Kabupaten Bolaang Mongondow Timur}

Perkawinan merupakan ikatan lahir dan batin yang memiliki tujuan dalam hidup agar terjalin rumah tangga yang sakinah mawaddah warrahmah, disisi lain juga rumah tangga dalam perkawinan akan menjadi harmonis dengan nilai-nilai yang terjalin dalam keluarga, begitu juga di desa nuangan 1 Kabupaten Bolaang Mongondow Timur adat Gama mengandung nilai-nilai nilai-nilai pendidikan Islam terhadap 13 tahapan pelaksanaan adat gama' di desa Nuangan 1 Kabupaten Bolaang Mongondow Timur ada beberapa tahapan adat Gama, yang mengandung nilai-nilai pendidikan Islam yaitu sebagai berikut:

1. Pangkoi Gama' : Pohon Ambil"

Pangkoi gama' dimna pengantin wanita dihiasi lengkap dengan pakaian pengantin,duduk di tengah-tengah ruangan dalam rumah, berkrudung menutup wajah dan dinaungi payung. nilai-nilai pendidikan Islam di dalam tahap pertama adat gama' sesuai dengan hasil wawancara dengan Tokoh agama desa Nuangan 1 Bapak Masuri Dakotalot S.Pd.i sebagai berikut: "Sifat dasar wanita itu dia halus, manja, pemalu, tegas dan juga harus dibahagiakan, di cintai,di sayangi dan di hargai". ${ }^{36}$ Berdasarkan hasil wawancara dengan tokoh agama desa Nuangan 1 Bapak Masuri Dakotalot S.Pd.i. maka penulis menyimpulkan nilai-nilai pendidikan Islam didalam tahapan pertama adat Gama' yaitu : wanita tidak boleh dikasari dan di marahi,wanita itu harus di bahagiakan, dicintai dan di sayangi.

2. Lolanan Kon Tutungan In Lanag: "meninggalkan rumah pengantin wanita"

Melewati tirisan rumah pengantin wanita di jemput keluarga penagntin pria dan menbujuk dengan halus sambil menyerahkan seserahan kepada penagntin wanita karena pengantin wanita masi malu-malu dengan rendah hati dan manja. Harga diri seorang wanita sengat tinggi sebagaimana. Harus bersifat halus kepada wanita dan memberikan sesuatu yang berharga. nilai-nilai pendidikan Islam di dalam tahap kedua adat gama' sesuai dengan hasil wawancara dengan Tokoh Agama Bapak Masuri Dakotalot S.Pd.i sebagai berikut: "Wanita memiliki harga diri yang tinggi maka bersikap baiklah kepada wanita" ${ }^{37}$ Berdasarkan hasil wawancara dengan tokoh agama

\footnotetext{
${ }^{36}$ Masuri Dakotalot S.Pd.i, Tokoh Agama Desa Nuangan 1. "Wawancara", 7 juni 2019.

${ }^{37}$ Masuri Dakotalot S.Pd.i, Tokoh Agama Desa Nuangan 1. "Wawancara”, 7 juni 2019.
} 
desa Nuangan 1 Bapak Masuri Dakotalot S.Pd.i. maka penulis menyimpulkan nilainilai pendidikan Islam didalam tahapan kedua adat Gama' yaitu : wanita memiliki harga diri yang tinggi sehingga menyikapi wanita dengan baik adalah keharusan dari laki-laki.

3. Lolanan Kon Tubig: "Melewati Sungai, Selokan”.

Tawar menawar dengan basa-basi yang halus antar anggota-anggota rombongan penjemput ( mogama') dengan anggota rombongan yang mengiringi pengantin wanita.Pengantin wanita berhenti karena harga diri sehingga merasa enggan unruk melakah lebih lanjut. Nilai-Nilai pendidikan Islam di dalam tahap ketiga adat gama' sesuai dengan hasil wawancara dengan Tokoh Agama Bapak Masuri Dakotalot S.Pd.i sebagai berikut: "Ditahap ini lebih menekankan lagi bahwa wanita itu derajatnya tinggi memiliki harga diri yang tinggi dan harus memberikan kebahagian kepada wanita di dunia dan akhirat". ${ }^{38}$ Berdasarkan hasil wawancara dengan tokoh agama desa Nuangan 1 Bapak Masuri Dakotalot S.Pd.i. maka penulis menyimpulkan nilainilai pendidikan Islam didalam tahapan ketiga adat Gama’ yaitu: derajat wanita sangat tinggi,memiliki harga diri yang tinggi, maka berbuat baik kepada wanita dan sayangi wanita.

4. Poponikan Kon Tukad : " menaiki bambambu"

Keluar penagntin pria menjemput dan memberikan seserahan sebagai tanda ikatan kekeluargaan Menjalani hubungan silaturahmi yang akrab, menggandeng tanagn pengantin wanita menuju pintu rumah dan berhenti di depan pintu. Nilai-Nilai pendidikan Islam didalam tahap keempat adat gama' sesuai dengan hasil wawancara dengan Tokoh Agama Bapak Masuri Dakotalot S.Pd.i sebagai berikut: "Mempererat ikatan hubungan kekeluargaan antar keluarga penagntin wanita dan keluraga pengantin pria dengan menyambut kedatangan rombongan keluarga pengantin wanita" ${ }^{39}$ Berdasarkan hasil wawancara dengan tokoh agama desa Nuangan 1 Bapak Masuri Dakotalot S.Pd.i. maka penulis menyimpulkan nilai-nilai pendidikan Islam didalam tahapan keempat adat Gama' yaitu: mempererat hubungan persaudaraan antara keluarga, dengan selalu menyambut kedatangan keluarga berkunjung kerumah. 5. Lampang Kon Tanom : " pengantin wanita sampe di teras rumah pengantin pria"

\footnotetext{
${ }^{38}$ Masuri Dakotalot S.Pd.i, Tokoh Agama Desa Nuangan 1. "Wawancara”, 7 juni 2019.

${ }^{39}$ Masuri Dakotalot S.Pd.i, Tokoh Agama Desa Nuangan 1. "Wawancara”, 7 juni 2019.
} 
Panagntin wanita disambut oleh Ibu kandung dan saudara kandung pengantin pria dengan gembira dan penuh kasi sayang diambang pintu rumah. Nilai-Nilai pendidikan Islam didalam tahap kelimaa dat gama' sesuai dengan hasil wawancara dengan Tokoh Agama Bapak Masuri Dakotalot S.Pd.i sebagai berikut: "Membangkitkan rasa percaya diri kepada penagantin wanita denagan sambutan kasi sayang oleh orang tua saudara kandung dan seluruh keluarga pengantin pria "40 Berdasarkan hasil wawancara dengan tokoh agama desa Nuangan 1 Bapak Masuri Dakotalot S.Pd.i. maka penulis menyimpulkan nilai-nilai pendidikan Islam didalam tahapan kelima adat Gama' yaitu: meperlakukan wanita dengan baik,menyayangi wanita dengan kasi sayang yang penuh akan membangkitkan derajat wanita.

6. Pilat In Paung: "menutup payung"

Pendamping wanita yang membawa payung menutup payung setelah keluarga pengantin pria memberikan seserahan kepada pengantin dan yang membawa payung sebagai tanda terimaksi. Nilai-Nilai pendidikan Islam didalam tahap keenamdat gama' sesuai dengan hasil wawancara dengan Tokoh Agama Bapak Masuri Dakotalot S.Pd.i sebagai berikut: "Penghargaan kepada pendamping wanita yang membawa payung sebagai tanda terimaksi sudah menaugi payung kepada pengantin wanita selama perjalanan dari rumah penagntin wanita menuju rumah pengantin pria" ${ }^{41}$ Berdasarkan hasil wawancara dengan tokoh agama desa Nuangan 1 Bapak Masuri Dakotalot S.Pd.i. maka penulis menyimpulkan nilai-nilai pendidikan Islam didalam tahapan keenam adat Gama' yaitu: saling mengaharga sesama manusi dengan usaha yang telah dilakukan.

7. Pilat In Siripu : "melepas sandal"

Pengantin wanita melepas sandal keluarga mempelai pria memberikan seserahan, namun pengantin wanita masi malu-malu dan manja untuk masuk kedalam rumah sehingga oaring tua kandung pengantin pria membujuk penagntin wanita untuk masuk kedalam ruamh. Nilai-Nilai pendidikan Islam didalam tahap ketujuh gama' sesuai dengan hasil wawancara dengan Tokoh Agama Bapak Masuri Dakotalot

\footnotetext{
40 Masuri Dakotalot S.Pd.i, Tokoh Agama Desa Nuangan 1. "Wawancara”, 7 juni 2019.

${ }^{41}$ Masuri Dakotalot S.Pd.i, Tokoh Agama Desa Nuangan 1. "Wawancara”, 7 juni 2019.
} 
S.Pd.i sebagai berikut: "Membuktikan bahwa sifat malu itu ada pada diri wanita ,harus menyikapi wanita dengan sehalus-halusnya dan jangan bersikap kasar kepada wanita "42 Berdasarkan hasil wawancara dengan tokoh agama desa Nuangan 1 Bapak Masuri Dakotalot S.Pd.i. maka penulis menyimpulkan nilai-nilai pendidikan Islam didalam tahapan ketujuh adat Gama' yaitu: wanita memiliki sifat malu maka berdikap baik kepada wanita dan jangan mengkasari wanita.

8. Ilitu’an / Bahasa'an Mopolitu : "pengantin wanita dipersilahkan duduk"

Pengantin wanita beserta pendamping di perintakan duduk oleh keluarga penagantin pria dengan bahasa yang halus dari pihak tuan rumah. Nilai-Nilai pendidikan Islam didalam tahap kedelapan gama' sesuai dengan hasil wawancara dengan Tokoh Agama Bapak Masuri Dakotalot S.Pd.i sebagai berikut: “Adab menerima tamu dengan sopan santun,bersikap baik kepada tamu yang berkunjung kerumah dengan mengharapkan berkah atas kunjungan dari tamu yang berkunjung"43

Berdasarkan hasil wawancara dengan tokoh agama desa Nuangan 1 Bapak Masuri Dakotalot S.Pd.i. maka penulis menyimpulkan nilai-nilai pendidikan Islam didalam tahapan pertama adat Gama' yaitu: menerima tamu yang berkunjung kerumah dan besikap baik kepada tamu untuk mengharapkan berkah dengan kunjungan tamu yang datang kerumah.

9. Pilat In Kokudung : "melepas kerudung"

Keuarga pengantin pria meminta pengantin wanita membuka penutup wajah disaksikan seluruh keluarga mempelai pria. Nilai-Nilai pendidikan Islam didalam tahap kesembilan gama' sesuai dengan hasil wawancara dengan Tokoh Agama Bapak Masuri Dakotalot S.Pd.i sebagai berikut: “memperkenalka penagantin wanita kepada keluarga mempelai pria bahwa penagntin pria betul-betul menemukan wanita idamanya". ${ }^{44}$ Berdasarkan hasil wawancara dengan tokoh agama desa Nuangan 1 Bapak Masuri Dakotalot S.Pd.i. maka penulis menyimpulkan nilai-nilai pendidikan Islam didalam tahapan sembilan adat Gama' yaitu: meperkenalkan pengantin wanita kepada keluarga pengantin pria lebih meberikan kepercayaan pengantin wanita.

10. Pinogapangan: "memberikan penghargaan kepada pendamping pengantin wanita"

\footnotetext{
${ }^{42}$ Masuri Dakotalot S.Pd.i, Tokoh Agama Desa Nuangan 1. "Wawancara", 7 juni 2019.

${ }^{43}$ Masuri Dakotalot S.Pd.i, Tokoh Agama Desa Nuangan 1. "Wawancara", 7 juni 2019.

${ }^{4}$ Masuri Dakotalot S.Pd.i, Tokoh Agama Desa Nuangan 1. "Wawancara”, 7 juni 2019.
} 
Keluarga mempelai pria memberikan seserahan berupa uang kepada pendamping wanita sebagai tanda rasa terimaksi sudah menemani penagantin wanita. serta mengharapkan karunia dari Allah Swt. Nilai-Nilai pendidikan Islam didalam tahap kesepuluh tahapan adat Gama’ desa Nuangan 1 sesuai dengan hasil wawancara dengan Tokoh Agama Bapak Masuri Dakotalot S.Pd.i sebagai berikut: "ucapan terimakasi karena sudah mendampingi penagntin wanita datang kerumah penagantin pria,dan salalu berIkhtiar untuk memperoleh pahala disisi Allah Swt " ${ }^{45}$ Berdasarkan hasil wawancara dengan tokoh agama desa Nuangan 1 Bapak Masuri Dakotalot S.Pd.i. maka penulis menyimpulkan nilai-nilai pendidikan Islam didalam tahapan kesepuluh adat Gama' yaitu: menghargai dan memberikan penghargaan kepada pendamping wanita sebagai tanda terimkasi sudah menemani pengantin wanita untuk berkunjung kerumah dan mengharapkan memperoleh pahala disisi Allah Swt.

11. Pinomama'an : "makan bersama"

Penagantin wanita diajak keluarga pengantin pria beserta keluarga makan bersama dan disediakan siri dan alat makan. Nilai-Nilai pendidikan Islam didalam tahap kesebelas gama' sesuai dengan hasil wawancara dengan Tokoh Agama Bapak Masuri Dakotalot S.Pd.i sebagai berikut: "Menjamu tamu denagan menagajak tamu makan, berperilaku baik kepada tamu yang datang bersilaturahmi kerumah adalah satu kewajiaban bagi tuan rumah dan merupakan adab menjamu tamu." ${ }^{46}$ Berdasarkan hasil wawancara dengan tokoh agama desa Nuangan 1 Bapak Masuri Dakotalot S.Pd.i. maka penulis menyimpulkan nilai-nilai pendidikan Islam didalam tahapan pertama adat Gama' yaitu: menjamu tamu dengan sebaik-baiknya,memberi mereka makan adalah suatu kewajiban tuan rumah.

12. Pokilimumugan : "Disuruh Berkumur"

Seorang Ibu dan semua keluarga dari pengantin pria memberikan seserahan berupah barang berharga sebahai tanda terimakasi terimakasi sudah mau menjadi pendamping hidup dari anak kami (penagantin pria)., selanjutnya disediakan tempat untuk tempat berkumur. nilai-nilai pendidikan Islam didalam tahap keduabelas gama' sesuai dengan hasil wawancara dengan Tokoh Agama Bapak Masuri Dakotalot S.Pd.i sebagai berikut: "Ringan tangan, artinya selalu memberikan yang terbaik kepada

\footnotetext{
${ }^{45}$ Masuri Dakotalot S.Pd.i, Tokoh Agama Desa Nuangan 1. "Wawancara”, 7 juni 2019.

${ }^{46}$ Masuri Dakotalot S.Pd.i, Tokoh Agama Desa Nuangan 1. "Wawancara”, 7 juni 2019.
} 
pengantin wanita dan orang yang mendampingi penagntin wanita' sebagai mana yang sering kita denganr syair yang berbunyi: tangan dibawa lebih baik dari pada tangan

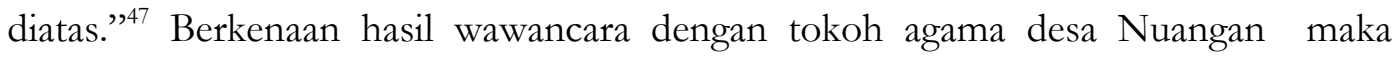
penulis menyimpulkan pada tahapan ke duabelas pelaksanaan adat gama' yaitu : ringan tangan artinya selalu memberi yang terbaik kepada wanita.

13. Pobuian : "Pulang"

Pendamping pengantin wanita izin pamit pulang kepada keluarga pengantin pria dan di barengi doa bersama yang di pimpin Ustadz yang sempat hadir. nilai-nilai pendidikan Islam didalam tahap keduabelas gama' sesuai dengan hasil wawancara dengan Tokoh Agama Bapak Masuri Dakotalot S.Pd.i sebagai berikut: "menutup rangkayan acara adat Gama' dengan doa dan mendoakan pengantin baru. ${ }^{48}$ Menanggapi hasil wawancar diatas maka penulis menyimpulkan bahwa : doa bersama dan mendoaakan pengantin bermasud mengharapkan berkah dan Ridho dari Allah Swt agar semua rangkaian pelaksanaan adat gama' dari awal samapai selesai diberkahi Allah Swt, serta mendoakan pengantin baru.

\section{Kesimpulan}

1. Adapun pandangan Islam terhadap adat gama dan tahapan pelaksanaan adat gama' di desa Nuangan 1 Kabupaten Bolaang Mongondow Timur, adapun pandangan Islam terhadap adat gama' Tidak bertantangan dengan ajaran Islam. Karena melihat tahapan pelaksanaan adat gama yang mengandung nilai-nilai Islam, yang meliputi: Memuliakan wanita, silaturahmi, tolong menolong dalam kebaikan, adab memuliakan tamu yang datang berkunjung kerumah, dan mendoakan pengantin yang baru saja menikah. Adapun Tahapan-tahapannya : Pangkoy gama' kemudian di lanjutkan dengan Polampangon Kontutugan Lanag (melangka keluar rumah), setelah itu Polampang kon tubig (meninggalakn halam rumah), dan menuju tahap berikutnya poponikan kon tugad (mulai masuk dihalaman rumah pengantin pria), kemudian lampang kon tanom (berhenti di depan pitu rumag), kemudian pilat in payung (menutup payung), dan pilat in siripu (melepas sandal), kemudian tamu dipersilahkan ilitu'an (tamu dipersilahkan duduk), dan meminta pengantin wanita untuk pilad in kokudung (melepas penutup

\footnotetext{
${ }^{47}$ Masuri Dakotalot S.Pd.i, Tokoh Agama Desa Nuangan 1. "Wawancara”, 7 juni 2019.

${ }^{48}$ Masuri Dakotalot S.Pd.i, Tokoh Agama Desa Nuangan 1. "Wawancara”, 7 juni 2019.
} 
wajah),kemudian para tamu diberikan pinogapangan (pemberian seserahan kepada pendamping), dan mempersilahkan tamu makan pinomamaan (makan bersama), dan pengantin wanita di suru berkumur pokilumumugan (berkumur), dan yang terakhir doa bersama pobuian (pulang).

2. nilai-nilai Pendidikan dalam 13 tahap adat gama' di desa Nuangan 1 Kabupaten Bolaang Mongondow didalamnya yang meliputi : berbuat baik kepada wanita, wanita memiliki harga diri yang tinggi, mempererat ikatan kekeluargaan, memuliakan wanita, saling membantu, saling menghargai, menjamu tamu yang datang kerumah,

\section{Implikasi Penelitian}

Berdasarkan hasil penelitian, pembahasan dan kesimpulan yang diperoleh maka dapat dijabarkan beberapa implikasi pemikiran yang berkaitan Pandangan Islam Terhadap Adat Gama' dan Nilai-Nilai Pendidikan (Studi pada desa Nuangan 1 Kabupaten Bolaang Mongondow Timur) sebagai berikut:

1. Implikasi teoritis

Berdasarkan hasil penelitian dapat memperkuat teori bahwa pamdamgam Islam terhadap adat gama' dan nilai-nilai pendidikan ada di dalam adat gama' di desa Nuangan 1, sehingga berdasarkan penelirtian ini dapat di jadikan bahan pertimbangan dari pihak desa umtuk lebih meningkatkan pengetahuan pengetahuan di desa Nuangan 1. hasil penelitian ini dapat dijadikan sebagai pengetahuan berkaitan dengan adat gama' di desa Nuangan 1.

2. Implikasi praktis

Hasil penelitian yang telah dilakukan tentang pandangan Islam terhadap Adat Gama' dan Nilai-Nilai yang terkandung didalamnya (Studi pada desa Nuangan 1 Kabupaten Bolaang Mongondow), dapat dijadikan sebagai sumber pengetahuan dapat memberirikan gambaran penelitian bagi peneliti yang berhubungan dengan pandangan Islam terhadap Adat Gama' dan nilai pendidikanya. Penelitian ini dapat dijadikan bekal pengetahuan bagi peneliti ketika Masyarakat Bertanya mengenai pandangan Isalam terhadap adat gama' dan nilai pendidikan.

\section{Daftar Pustaka}


Achmadi, Idiologi Pendidikan Islam; Paradigma Humanisme Teosentris, Yogyakarta: Pustaka Belajar, 2005.

Alhabsyi, Abubakar, Sekertaris Desa Nuangan 1. "Wawancara”, 4 Juni 2019.

Arikunto Suharsimi, Prosedur Penelitian Ilmiah, Suatu Pendekatan Praktek Ed, II; Cet. IX; Jakarta: bineka Cipta, 2008.

Arsip Profil Desa Nuangan I Kecamatan Nuangan I Kab Boltim.

Baihaqi, Abubakar al-, Syi'bu al_Iman, ( Riyad: Maktaba al-Rusdu,2003), 10/ 114, nomor hadist 7250 .

Clifford, Geertz,Kebudayaan dan Agama, Yogyakarta: Kanisius, 2015.

Departemen Pendidikan dan Kebudayaan, Kamus Besar Bahasa Indonesia Edisi kedua, Jakarta; Balai Pustaka, 2009.

Djumransjah. M, Filasafat Pendidikan Malang: Bayumedia Publishing, 2004.

Elizabeth, Houldsworth, 2007. "Mengelola Kinerja". People mengoment: Teori dan Strategi (Tantangan dan Peluang). Rees, David, Richard McBain. Eds. 2007. Dialihbahasakan: Sukono, Disunting: Tri Wibowo B.S. Cet. 1. Jakarta: Kencana Prenada Media Group.

Eslen Mursal, Kajian transformasi budaya, Bandung: Angkasa, 2008.

Fuad T Bazmul, Kepala Desa Nuangan I. “Wawancara”, 4 Juni 2019.

Hadi Sutrisno, Metodoligi Research, Jilid I, Cet; XXIX; Yogyakarta: Andi Yogyakarta, 2009.

Hidayat Achmad R., The Holy Qur'an Terjemah Tafsir Perkata Kode Tajwid Rarab, Jakarta; PT. Insan Media Pustaka, 2013.

Ibnu Mazah, Sunan Ibnu Mazah, (tt.p: Dar Ihya al-Kitab al-Arabiyah,t.t), 1/ 636, nomor hadist 1977.

Indriantoro Nur dan Bambang Supomo, Metodologi Penelitian Bisnis Untuk Akutansi dan Menejemen, Ed I; Yogyakarta, BPFE UGM, 2009.

Marimba D Ahmad. Pengantar Filsafat Pendidikan Islam. Bandung: Al-Ma`Arif, 2011

Manto dan Sinta, Undangan adat Gama',Nuangan 12015

Milles Matthew B, Et.Al, Qualitative Data Analisys, diterjamahkan oleh Tetjep Rohendi Rohidi Dengan Judul Analisis Data Kualitatif, Buku Tentang MetodeMetode Baru Cet.I; Jakarta: UI - Press, 2007. 
Mudjahirin, 2006, Orang Islam Jawa Pesisiran, Semarang: Fasindo \& Puslit Sosial Budaya Lembaga Penelitian Universitas Diponegoro.

Muhaimin, 2008, Paradigma Pendidikan Islam, Bandung: Remaja Rosda Karya, Bandung.

Muhaimin, Paradigma Pendidikan Islam, Bandung: PT Remaja Rosdakarya, 2002.

Muhammad Bin Ismail Abu Abdillah al-Bukhari, Sabib Buhari, (tt.p: Dar Tauqi anNazah, 1442), 8/11, nomor hadist 6018.

Munawir, Ahmad Warson, al-Munawir, Kamus Bahasa Arab Indonesia, Surabaya, Pustaka Progresif, 2010.

Nata Abuddin, Metodologi Studi Islam Jakarta: Rajawali Press, 2012. , Metodologi Studi Islam, Jakarta: PT, Raja Grafindo Persada,2010.

Paputungan, Asirin, Ketua Adat Desa Nuangan I Kecamatan Nuangan Kabupaten Bolaang Mongondow Timur. "Wawancara”, 3 Juni 2019.

Rosyadi Khoiron, Pendidikan Profetik, Yogyakarta: Pustaka Belajar, 2004.

Sugiyono, Metode Penelitian Bisnis, Bandung, Alfabeta, 2008.

Suparlan, Kebudayaan, Masyarakat dan Agama sebagai Sasaran Penelitian Antropologi, Jakarta: PLPA Departemen Agama RI, 2013.

Surahmat Winarso, Pengantar Penelitian-Penelitian Dasar Metode Teknike Bandung, 2007.

Surakhmad Winarno, Dasar dan Teknik Research, Pengantar Metodologi Ilmiah Ed, VI ; Bandung: Tarsito, 2012.

Suyudi M, Pendidikan dalam Prespektif Al-Quran, Yogyakrta: mikraj, 2005.

Tafsir Ahmad, Ilmu Pendidikan dalam Perspektif Islam, Bandung: Rosda Karya, 2005.

Winarso, Pengantar Penelitian-Penelitian Dasar Metode Teknike Bandung, 1989.

Young, Pai, Cultural Foundations of Education, Kansas: University of Missouri, 2007.

Zubaedi. 2011. Desain Pendidikan Karakter Konsepsi dan Aplikasinya dalam Lembaga Pendidikan. Jakarta: Kencana. 